\title{
Usefulness of microRNA-375 as a prognostic and therapeutic tool in esophageal squamous cell carcinoma
}

\author{
YUKA ISOZAKI, ISAMU HOSHINO, YASUNORI AKUTSU, NAOYUKI HANARI, MIKITO MORI, \\ TAKANORI NISHIMORI, KENTARO MURAKAMI, NAOKI AKANUMA, NOBUYOSHI TAKESHITA, \\ TETSURO MARUYAMA, TAKESHI TOYOZUMI, MASAHIKO TAKAHASHI, \\ HIROSHI SUITO and HISAHIRO MATSUBARA
}

Department of Frontier Surgery, Chiba University Graduate School of Medicine, Chiba 260-8670, Japan

Received September 18, 2014; Accepted October 30, 2014

DOI: $10.3892 /$ ijo.2014.2789

\begin{abstract}
The aim of this study was to clarify the importance of microRNA-375 (miR-375) expression in patients with esophageal squamous cell carcinoma (ESCC) and to examine the in vivo antitumor effects of miR-375 in a model of ESCC using a non-viral delivery system. We estimated the miR-375 and LDHB and AEG-1/MTDH mRNA expression of the ESCC tumors from 85 patients. The correlation between the miR-375 expression and clinicopathological features, including the prognosis, were evaluated. The presence of high miR-375 expression was associated with lymphatic vessel invasion, while a low expression of miR-375 significantly correlated with a poor prognosis for the 85 ESCC patients. We also found that there was a significant inverse correlation between the expression of miR-375 and that of LDHB. Before the examination of miR-375 in the in vivo assay, we confirmed that atelocollagen prolonged the accumulation of miRNA by using fluorescently-labeled miRNA and an in vivo imaging system. We injected the miR-375/atelocollagen complex or a control-miRNA/atelocollagen complex into mice bearing TE2 and T.Tn xenografts via subcutaneous (s.c.) injections. The growth of both the TE2 and T.Tn tumors in the miR-375 groups was significantly suppressed compared with that in the control-miRNA groups. In addition, The LDHB mRNA expression of TE2 xenografts was significantly downregulated after miR-375 treatment. In conclusion, it might be possible for the level of miR-375 expression to be a utilized as a prognostic indicator for ESCC patients. The administration of miR-375 using a non-viral delivery might represent a powerful new treatment for ESCC.
\end{abstract}

Correspondence to: Dr Isamu Hoshino, Department of Frontier Surgery, Chiba University Graduate School of Medicine, Inohana 1-8-1, Chuo-ku, Chiba 260-8670, Japan

E-mail: i_hosino@chiba-u.jp

Key words: microRNA-375, tumor-suppressive microRNA, esophageal squamous cell carcinoma, delivery system, microRNA-based therapy

\section{Introduction}

Esophageal squamous cell carcinoma (ESCC) is the most common type of esophageal cancer in Japan. Despite recent advances in the use of combinations of chemo- and radiotherapy, ESCC remains one of the most lethal malignancies worldwide, and has a five-year survival rate of only $20-40 \%$ even after curative surgery $(1,2)$. Nucleic acid-based therapy is a promising new approach, and the development of such a therapy might improve the morbidity and mortality of ESCC.

Epigenetic changes, such as DNA methylation, histone modifications and miRNA biogenesis, regulate gene expression (3). Histone deacetyltransferases, which deacetylate the lysine residues of histone proteins, facilitate the access of many transcriptional factors to DNA and consequently suppress the expression of the target genes $(4,5)$. Histone deacetylase inhibitors (HDACIs) are anticancer agents with a potent HDAC-inhibiting activity $(4,5)$. Numerous HDACIs have been identified and some of which have recently been used in clinical trials of cancer treatment (6). The microRNAs (miRs) are non-coding RNAs that are 21-25 nucleotides in length that silence gene expression, usually by targeting mRNAs for cleavage or translational repression (7). They are known to be involved in gene functions in a broad range of biological processes, including development, cell differentiation, proliferation, apoptosis, metabolism, carcinogenesis and growth control (8-11).

Studies have analyzed the function of microRNA-375 (miR-375) as a tumor suppressor in head and neck squamous cell carcinoma, maxillary sinus squamous cell carcinoma, hepatocellular cancer, pancreatic cancer and other cancers (12-15). Some of them reported that miR-375 plays a tumor-suppressive role in various cancers (12-15). On the other hand, miR-375 was upregulated in the tumor tissue from prostate cancer and papillary thyroid carcinoma, which revealed that the upregulation of miR-375 can serve as a novel marker of these cancers $(16,17)$.

We have reported that the expression of miR-375 in HDACI-treated cells was upregulated $>400$-fold in ESCC cell lines (18). This result indicates the possibility that the transcription of miRs is regulated by histone modification, similar to that observed in other forms of gene transcription. 
The miR-375 expression in ESCC was lower than that in the normal epithelium. miR-375 inhibits the proliferation, migration and invasion of ESCC cells. Moreover, we showed that $L D H B$ and $A E G-1 / M T D H$ were miR-375-targeted genes. Clinical specimens of ESCC exhibited a high level of $L D H B$ expression at both the mRNA and protein levels. Knockdown of $L D H B$ by RNA interference (RNAi) showed that it had a tumor-suppressive function in ESCC cells. $L D H B$, which is regulated by the tumor-suppressive miR-375, may therefore act as an oncogene in ESCC (18).

However, the correlation between miR-375 expression and the clinicopathological features of ESCC have been unclear. In addition, the relationship between miR-375 expression and $L D H B$ and $A E G-1 / M T D H$ mRNA expression in ESCC specimens has not yet been examined. Nor has the tumor-suppressive effect of miR-375 on ESCC been examined in in vivo assays.

The aim of this study was to clarify the correlations between the expression of miR-375 and the clinicopathological features of ESCC, the $L D H B$ and $A E G-1 / M T D H$ mRNA expression in ESCC and to elucidate the tumor-suppressive effect of miR-375 in vivo, in assays using a non-viral delivery system.

\section{Materials and methods}

Clinical ESCC specimens. ESCC specimens and normal epithelial tissue specimens were collected from 85 patients who underwent surgical treatment for histologically proven ESCC in the Department of Frontier Surgery, Chiba University Graduate School of Medicine (Chiba, Japan), from 2001 to 2012. All patients gave their informed consent for tissue donation. Surgical treatments were performed without any preoperative radio- or chemotherapy. Normal esophageal epithelial tissue specimens were obtained far from the cancer. After excision, the tissue specimens were immediately frozen in liquid nitrogen until the subsequent analysis. The clinical stage of ESCC was assessed on the basis of the tumor-node-metastasis (TNM) classification system recommended by the International Union Against Cancer (7th edition, 2009).

RNA extraction. The tissue specimens were treated with the TRIzol reagent (Invitrogen Life Technologies, Carlsbad, CA, USA), according to the manufacturer's instructions, for total RNA extraction. The purity and concentration of all RNA samples were evaluated by their absorbance ratio at 260/280 $\mathrm{nm}$, which was determined with a NanoDrop ND-1000 spectrophotometer (NanoDrop Technologies, Inc., Rockland, DE, USA).

Real-time quantitative RT-PCR for measuring the miR-375 expression. The expression of miR-375 was determined by quantitative RT-PCR using TaqMan ${ }^{\circledR}$ MicroRNA Assay kits (Applied Biosystems, Foster City, CA, USA). First-strand cDNA was synthesized from $10 \mathrm{ng}$ of total RNA for each sample. The individual assays used a $15 \mu \mathrm{l}$ reaction mixture containing $5 \mu \mathrm{l}$ of RNA extract, $0.15 \mu \mathrm{l}$ of $100 \mathrm{mM}$ dNTPs, $1 \mu \mathrm{l}$ of MultiScribe Reverse Transcriptase (50 U/ $\mu \mathrm{l}), 1.5 \mu \mathrm{l}$ of $10 \mathrm{X}$ reverse transcription buffer, $0.19 \mu \mathrm{l}$ of RNase inhibitor $(20 \mathrm{U} / \mu \mathrm{l}), 1 \mu \mathrm{l}$ of gene-specific TaqMan primer and $4.16 \mu \mathrm{l}$ of nuclease-free water according to the manufacturer's instructions. The reaction mixture was incubated at $16^{\circ} \mathrm{C}$ for $30 \mathrm{~min}, 42^{\circ} \mathrm{C}$ for $30 \mathrm{~min}$ and $85^{\circ} \mathrm{C}$ for $5 \mathrm{~min}$ and $4^{\circ} \mathrm{C}$ until use. Subsequently, $1.33 \mu \mathrm{l}$ of the DNA template was amplified using $10 \mu \mathrm{l}$ of TaqMan Universal PCR Master Mix, $7.67 \mu 1$ of nuclease-free water and $1 \mu \mathrm{l}$ of gene-specific TaqMan primers/probe mix in a final volume of $20 \mu 1$. The amplification, detection and data analysis were performed with the iCycler IQ Real-Time Detection System (Bio-Rad, Hercules, CA, USA). The reaction mixture was incubated at $95^{\circ} \mathrm{C}$ for $10 \mathrm{~min}$, followed by 40 cycles of $95^{\circ} \mathrm{C}$ for $15 \mathrm{sec}$ and $60^{\circ} \mathrm{C}$ for $60 \mathrm{sec}$. The RT-qPCR experiments were performed in duplicate. The expression of RNU6B was used as internal control.

Real-time quantitative RT-PCR to assess the mRNA expression of $L D H B$ and $A E G-1 / M T D H$. The mRNA expression levels of $L D H B$ and $A E G-1 / M T D H$ were examined by real-time quantitative PCR. The cDNA templates for real-time PCR were synthesized from $1 \mu \mathrm{g}$ of total RNA using a High Capacity RNA-to-cDNA kit (Applied Biosystems). The Actin $\alpha 1$ (ACTAl) gene served as an internal control. The PCR reaction consisted of SsoFast EvaGreen Supermix (containing dNTPs, Sso7d fusion polymerase, $\mathrm{MgCl}_{2}$, EvaGreen dye and stabilizers; Bio-Rad), $1 \mu \mathrm{M}$ each primer and cDNA. All reactions were run in duplicate on the MyiQ2 Two-Color Real-Time PCR Detection System (Bio-Rad). The PCR process was as follows: initial denaturation at $95^{\circ} \mathrm{C}$ for $30 \mathrm{sec}$, followed by 40 cycles of denaturation at $95^{\circ} \mathrm{C}$ for $5 \mathrm{sec}$ and annealing at $55^{\circ} \mathrm{C}$ for $10 \mathrm{sec}$. The following primer sequences were used: LDHB, 5'-TGG CGTGTGCTATCAGCATT-3' and 5'-GCTTATCTTCCA AAACATCCACAAG-3'; AEG-1/MTDH, 5'-TCCGAGAAG CCCAAACCAAAT-3' and 5'-CTTCACCCTCAGCCACTT CAA-3'; ACTA1, 5'-CCTTCATCGGTATGGAGTC-3' and 5'-GTTGGCATACAGGTCCTT-3'. The comparative cycle threshold $\left(\mathrm{C}_{\mathrm{T}}\right)$ method was applied to quantify the expression levels of the mRNAs. The relative amount of $L D H B$ and $A E G-1 / M T D H$ to ACTA1 mRNA was calculated using the $2^{-\Delta \mathrm{CT}}$ equation, where $\Delta \mathrm{C}_{\mathrm{T}}=\left(\mathrm{C}_{\mathrm{T} \text { LDHB or AEG-1/MTDH }}-\mathrm{C}_{\mathrm{T} \text { ACTA1 }}\right)$.

Statistical analysis. The correlation(s) between the expression of miR-375 and the clinicopathological factors were assessed by the $\chi^{2}$ test. The overall survival was calculated as the time from the surgical treatment until death or the last follow-up date. The correlation between the overall survival and the expression of miR-375 was calculated using the log-rank test, and the results are presented as curves determined using the Kaplan-Meier method. A linear regression analysis was performed to determine whether there was a correlation between the expression of miR-375 and the mRNA expression of $L D H B$ and $M T D H$.

Validation of the prolonged accumulation of miRNA in xenografts by atelocollagen. To examine the antitumor effects of miR-375 in an in vivo assay, we selected atelocollagen (Atelogene ${ }^{\circledR}$; Koken Co., Ltd., Tokyo, Japan) as a non-viral delivery system. To explore the effects of atelocollagen on the accumulation of the miRNA, we prepared two types of tumor-bearing mice, those bearing a fluorescently-labeled miRNA $(10 \mu \mathrm{M}) /$ atelocollagen complex and those bearing a fluorescently-labeled miRNA $(10 \mu \mathrm{M}) / \mathrm{PBS}$ complex. Alexa Fluor 555, premiR-Neg and Pre-miR miRNA Precursor (all from Life Technologies, Grand Island, NY, 
USA) was used as the fluorescently-labeled miRNA. The fluorescently-labeled miRNA was adjusted to a concentration of $10 \mu \mathrm{M}$. Equal volumes of atelocollagen (0.1\% in PBS at $\mathrm{pH}$ 7.4) and fluorescently-labeled miRNA solution were combined and mixed by rotating for $20 \mathrm{~min}$ at $4^{\circ} \mathrm{C}$. The labeled miR and PBS complex was prepared in an identical manner. We injected $200 \mu \mathrm{l}$ of fluorescently-labeled miRNA $(10 \mu \mathrm{M}) /$ atelocollagen complex into one tumor-bearing mouse and the fluorescently-labeled miRNA $(10 \mu \mathrm{M}) / \mathrm{PBS}$ complex into another mouse via subcutaneous (s.c.) injection. Fifteen minutes and $24 \mathrm{~h}$ after the injection, we observed the fluorescence signal using an in vivo imaging system (IVIS) ${ }^{\circledR}$.

In vivo assay of the effects of the non-viral delivery of $m i R-375$

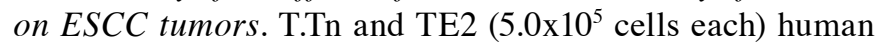
ESCC cells were injected into the backs of BALB/c nu/nu mice. When the estimated tumor volume reached $\sim 300 \mathrm{~mm}^{3}$, mice were randomly divided into four groups containing five animals each.

The miR-375 and negative control miRNA were obtained from Bonac Corp. (Fukuoka, Japan). Both the miR-375 and negative control miRNA levels were adjusted to a concentration of $10 \mu \mathrm{M}$. To prepare the miR-375 $(10 \mu \mathrm{M})$ /atelocollagen and control-miR $(10 \mu \mathrm{M}) /$ atelocollagen complex, equal volumes of atelocollagen (0.1\% in PBS at $\mathrm{pH} 7.4)$ and miR solution were combined and mixed by rotating for $20 \mathrm{~min}$ at $4^{\circ} \mathrm{C}$. Five weeks after tumor injection, we injected the mice with $200 \mu \mathrm{l}$ of the miR-375/atelocollagen or control-miRNA/atelocollagen complex by s.c. injection. The treatment was performed twice a week for a total of six injections. The tumor size was measured in two dimensions using calipers, and the tumor volume $\left(\mathrm{mm}^{3}\right)$ was calculated as $\mathrm{a}^{2} \mathrm{x} \mathrm{b} / 2 \mathrm{~mm}^{3}$ (a, minor axis; $b$, major axis). The tumor size was measured for 22 days.

The Animal Research Committee of the Chiba University, Japan, approved all studies. All animal procedures were performed according to the guidelines for the Animal Research Committee of the Chiba University, Japan. Either was used for mouse euthanasia and anesthesia.

Determination of the LDHB and AEG-1/MTDH mRNA expression in tumors treated with the miR-375/atelocollagen and control-miR/atelocollagen complex. We prepared TE2 and T.Tn tumor-bearing mice, and divided them into four groups containing three animals each. As stated above, we injected the miR-375/atelocollagen or control-miRNA/atelocollagen complex into the xenografts by s.c. injection. The treatment was conducted one time, and the tumors were excised $24 \mathrm{~h}$ after the treatment. We extracted total RNA from the tumors and determined the $L D H B$ and $A E G-1 / M T D H$ mRNA expression level. The mRNA expression level of these genes was compared between the miR-375 and control-miRNA groups.

\section{Results}

The correlation between the expression of miR-375 in ESCC specimens and the clinicopathological factors. We performed RNA extraction and RT-PCR on ESCC specimens and normal epithelial tissue specimens from 85 patients (Table I). We examined the correlations between the miR375 expression and various clinicopathological factors, including the patient
Table I. Statistical features of ESCC patients.

\begin{tabular}{|c|c|}
\hline Characteristics & No. \\
\hline Total & 85 \\
\hline \multicolumn{2}{|l|}{ Age } \\
\hline$\leq 65$ & 37 \\
\hline$>65$ & 48 \\
\hline \multicolumn{2}{|l|}{ Gender } \\
\hline Male & 70 \\
\hline Female & 15 \\
\hline \multicolumn{2}{|l|}{ Location } \\
\hline $\mathrm{Ph}$ & 1 \\
\hline $\mathrm{Ce}$ & 3 \\
\hline Ut & 8 \\
\hline Mt & 32 \\
\hline $\mathrm{Lt}$ & 36 \\
\hline $\mathrm{Ae}$ & 4 \\
\hline Unknown & 1 \\
\hline \multicolumn{2}{|l|}{ pT factor } \\
\hline $\mathrm{T} 1$ & 27 \\
\hline $\mathrm{T} 2$ & 8 \\
\hline $\mathrm{T} 3$ & 38 \\
\hline $\mathrm{T} 4$ & 12 \\
\hline \multicolumn{2}{|l|}{$\mathrm{pN}$ factor } \\
\hline N0 & 35 \\
\hline N1 & 27 \\
\hline $\mathrm{N} 2$ & 14 \\
\hline N3 & 7 \\
\hline $\mathrm{N} 4$ & 2 \\
\hline \multicolumn{2}{|c|}{ Lymphatic vessel invasion } \\
\hline 0 & 39 \\
\hline 1 & 26 \\
\hline 2 & 12 \\
\hline 3 & 8 \\
\hline \multicolumn{2}{|l|}{ Vessel invasion } \\
\hline 0 & 26 \\
\hline 1 & 21 \\
\hline 2 & 27 \\
\hline 3 & 11 \\
\hline \multicolumn{2}{|l|}{ Pathology } \\
\hline Wel & 22 \\
\hline Mod & 46 \\
\hline Por & 13 \\
\hline Other & 4 \\
\hline \multicolumn{2}{|l|}{ pUICC stage } \\
\hline I & 22 \\
\hline II & 18 \\
\hline III & 44 \\
\hline IV & 1 \\
\hline
\end{tabular}

The $\mathrm{pT}$ and $\mathrm{pN}$ factor, and pUICC stage are described according to the International Union Against Cancer (UICC) tumor-node-metastasis (TNM) Classification (7th edition, 2009). ESCC, esophageal squamous cell carcinoma; $\mathrm{Ph}$, pharynx; $\mathrm{Ce}$, cervical esophagus; $\mathrm{Ut}$, upper thoracic esophagus; Mt, middle thoracic esophagus; Lt, lower thoracic esophagus; Ae, abdominal esophagus; Wel, well differentiated; Mod, moderately differentiated; Por, poorly differentiated. 
Table II. The correlation between the expression of miR-375 in ESCC specimens and clinicopathological factors.

\begin{tabular}{|c|c|c|c|}
\hline Clinicopathological feature & Low & High & P-value \\
\hline \multicolumn{4}{|l|}{ Age } \\
\hline$\leq 65$ & 7 & 30 & \multirow[t]{2}{*}{0.8108} \\
\hline$>65$ & 7 & 41 & \\
\hline \multicolumn{4}{|l|}{ Gender } \\
\hline Male & 11 & 59 & \multirow[t]{2}{*}{0.982} \\
\hline Female & 3 & 12 & \\
\hline \multicolumn{4}{|l|}{ pT factor } \\
\hline $\mathrm{T} 1$ & 3 & 24 & \multirow[t]{2}{*}{0.5327} \\
\hline $\mathrm{T} 2,3,4$ & 11 & 47 & \\
\hline \multicolumn{4}{|l|}{$\mathrm{pN}$ factor } \\
\hline No & 4 & 31 & \multirow[t]{2}{*}{0.5327} \\
\hline $\mathrm{N} 1,2,3$ & 10 & 40 & \\
\hline \multicolumn{4}{|l|}{ Lymphatic vessel invasion } \\
\hline 0 & 3 & 36 & \multirow[t]{2}{*}{0.0352} \\
\hline $1,2,3$ & 11 & 35 & \\
\hline \multicolumn{4}{|l|}{ Vessel invasion } \\
\hline 0 & 4 & 22 & \multirow[t]{2}{*}{0.8901} \\
\hline $1,2,3$ & 10 & 49 & \\
\hline \multicolumn{4}{|l|}{ Pathology } \\
\hline Wel & 2 & 20 & \multirow[t]{4}{*}{0.8803} \\
\hline Mod & 9 & 37 & \\
\hline Por & 3 & 10 & \\
\hline Other & 0 & 4 & \\
\hline \multicolumn{4}{|l|}{ pUICC stage } \\
\hline I & 3 & 19 & \multirow[t]{2}{*}{1} \\
\hline II, III, IV & 11 & 52 & \\
\hline
\end{tabular}

The significance was assessed by the $\chi^{2}$ test. The $\mathrm{pT}$ and $\mathrm{pN}$ factor, and pUICC stage are described according to the UICC (International Union Against Cancer) tumor-node-metastasis (TNM) Classification (7th edition, 2009). miR-375, microRNA-375; ESCC, esophageal squamous cell carcinoma; Wel, well differentiated; Mod, moderately differentiated; Por, poorly differentiated.

age, gender, $\mathrm{T}$ and $\mathrm{N}$ factor, lymphatic vessel and vessel invasion, stage and differentiation. High expression of miR-375 was significantly correlated with lymphatic vessel invasion $(\mathrm{P}=0.0352)$. None of the other factors were found to be significantly related to the miR-375 expression (Table II).

Low expression of miR-375 was significantly correlated with a poor prognosis. We also performed a statistical analysis of the correlation between the expression of miR-375 and the prognosis of the 85 patients. The low expression of miR-375 was significantly correlated with a poor prognosis $(\mathrm{P}=0.007)$. In the group of patients with high miR-375 expression, the five-year survival rate was $58.2 \%$, while that in the group with low miR-375 expression was $23.1 \%$ (Fig. 1).

A significant inverse correlation exists between the miR-375 expression and LDHB mRNA expression in ESCC

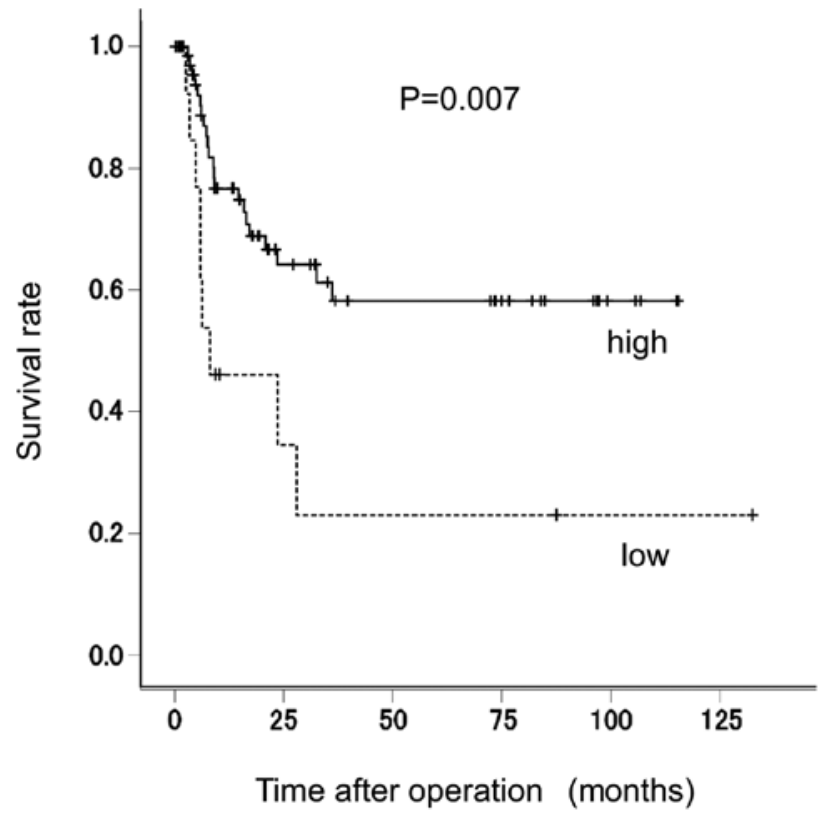

Figure 1. The correlation between the overall survival and the expression of microRNA-375 (miR-375) was determined by the log-rank test, and data are presented as curves determined using the Kaplan-Meier method. The low expression of miR-375 was significantly correlated with a poor prognosis $(\mathrm{P}=0.007)$. The five-year survival rate in the high miR-375 expression group was $58.2 \%$, while it was $23.1 \%$ in the low miR-375 expression group.

specimens. We next examined the correlation between the expression of miR-375 and the mRNA expression levels of $L D H B$ and $A E G-1 / M T D H$ using a linear regression analysis. We found that there was a significant inverse correlation between the expression of miR-375 and that of $L D H B$ $(\mathrm{P}=0.039)$. No significant correlation was observed with the $A E G-1 / M T D H$ expression levels, although there was a tendency for an inverse correlation with the miR-375 expression $(\mathrm{P}=0.149)$ (Fig. 2).

Atelocollagen prolongs the accumulation of miRNA in xenograft tumors. We next examined whether atelocollagen could prolong the accumulation of miRNA in the tumor using a fluorescently-labeled miRNA and the IVIS imaging system. Fifteen minutes after injection of the atelocollagen or PBS-miRNA mixture, both xenografts exhibited the accumulation of fluorescence. After $24 \mathrm{~h}$, we observed the accumulation of fluorescence in the tumors injected with the fluorescently-labeled miRNA $(10 \mu \mathrm{M}) /$ atelocollagen complex, but the fluorescence was not observed in another mouse that was injected with fluorescently-labeled miRNA (10 $\mu \mathrm{M}) /$ PBS (Fig. 3).

In vivo effects of miR-375 on ESCC tumors. As shown in Fig. 4, 22 days after the first treatment, the growth of both TE2 and T.Tn tumors in the miR-375/atelocollagen complex groups were significantly suppressed compared with the miR-control groups. The average volume of TE2 xenografts in the control-miR/atelocollagen complex group was $1,900.8 \mathrm{~mm}^{3}$, while that of the TE2 xenografts in the miR-375/atelocollagen complex group was $668.0 \mathrm{~mm}^{3}$. The miR-375/atelocollagen complex therefore suppressed the growth of the TE2 xenografts by $64.8 \%$. For the T.Tn xenografts, the average volume 

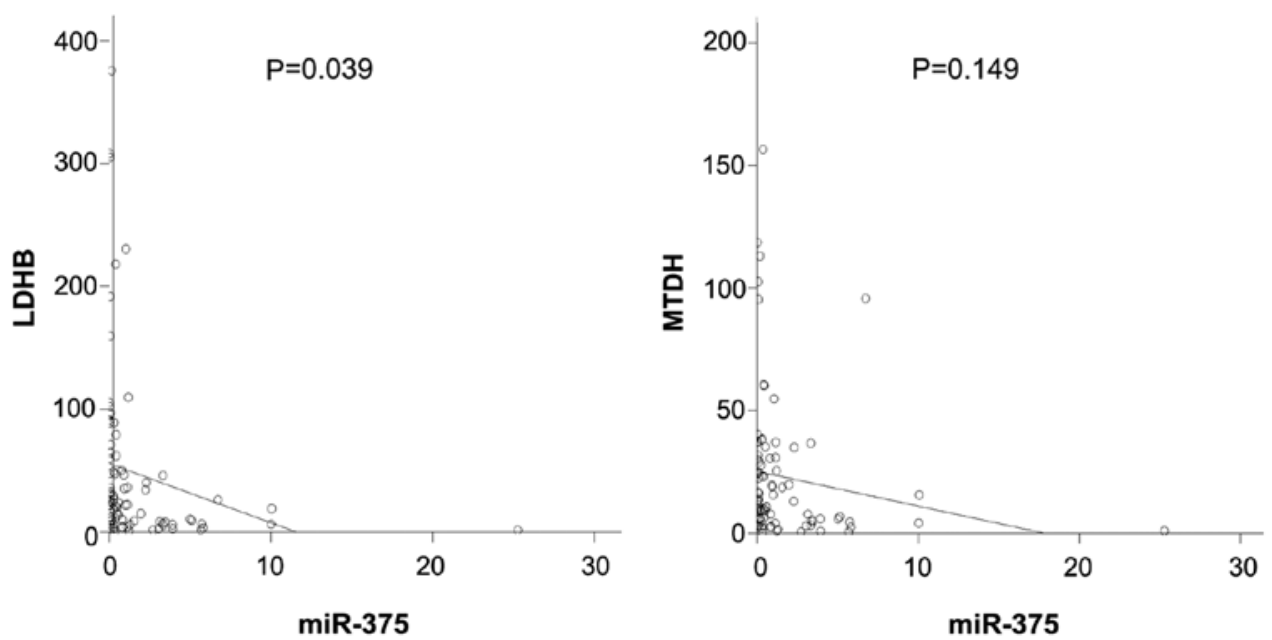

Figure 2. A linear regression analysis was performed to identify the correlation between the expression of microRNA-375 (miR-375) and the mRNA expression of $L D H B$ and $A E G-1 / M T D H$. The miR-375 expression was significantly inversely correlated with the $L D H B$ mRNA expression ( $\mathrm{P}=0.039)$. No significant correlation was observed with regard to the $A E G-1 / M T D H$ expression levels, although there was a tendency for an inverse correlation with the miR-375 expression $(\mathrm{P}=0.149)$.

Fluorescent-labeled miRNA/ atelocollagen complex

Fluorescent-labeled miRNA/ PBS
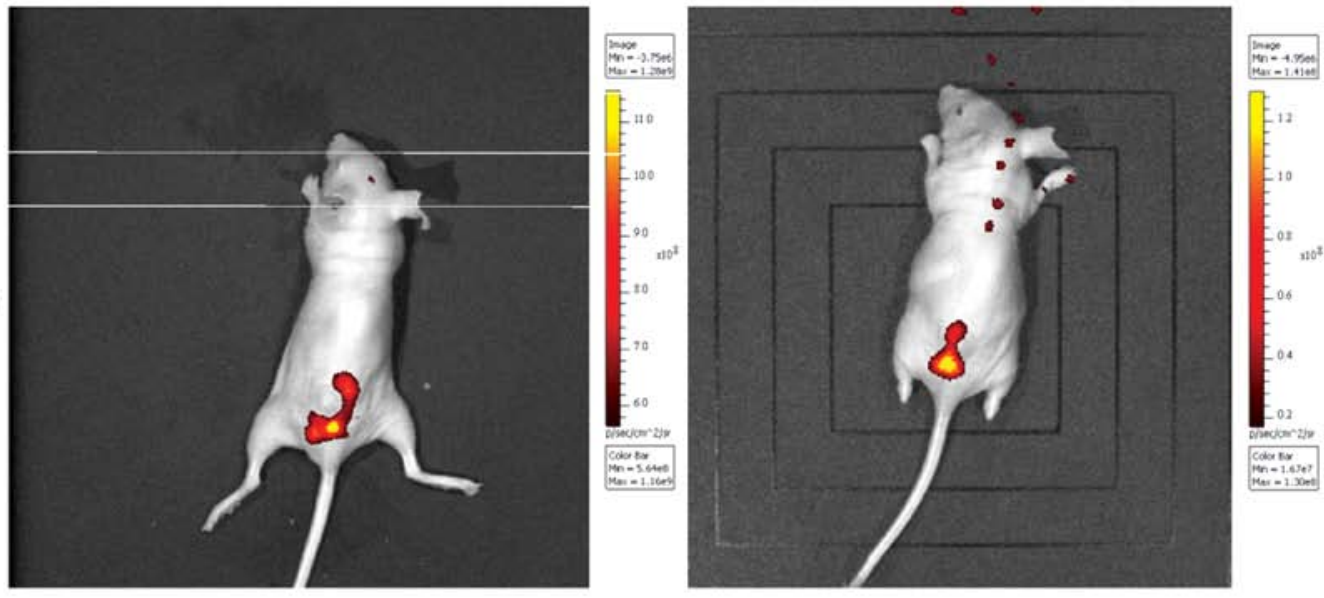

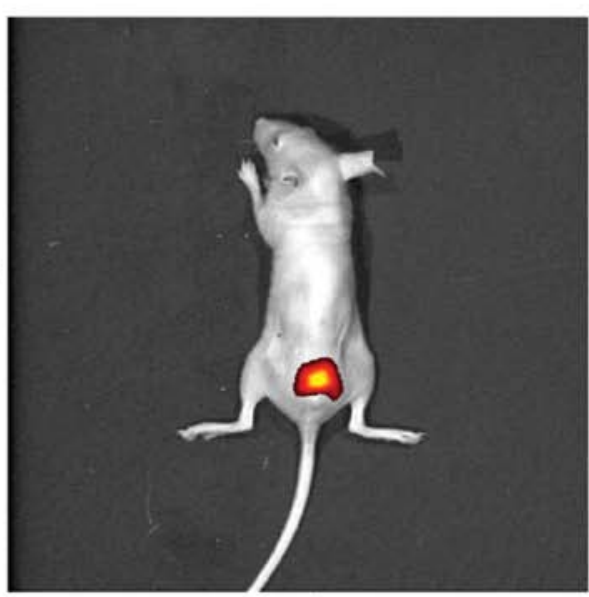

$15 \min$
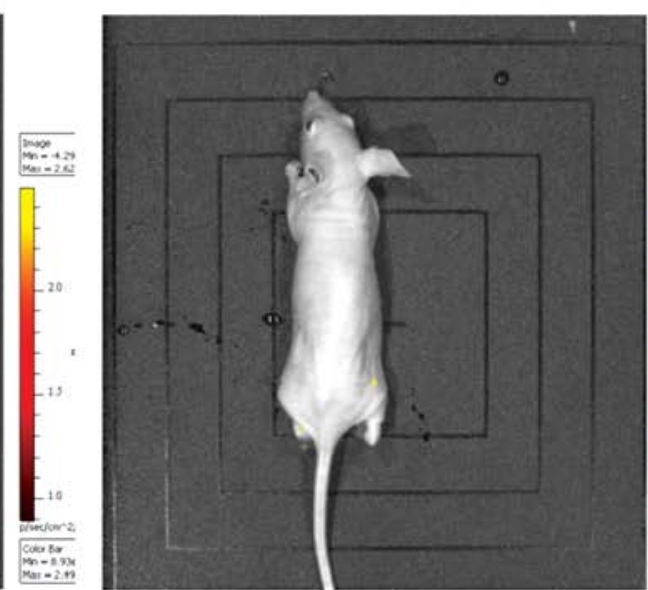

$24 \mathrm{~h}$

Figure 3. Using an in vivo imaging system, we confirmed that atelocollagen prolonged the accumulation of the fluorescently-labeled miRNA in the tumor. After $15 \mathrm{~min}$, the tumor xenografts treated with both the fluorescently-labeled miRNA/atelocollagen and miRNA/PBS complex exhibited the accumulation of fluorescence. After $24 \mathrm{~h}$, the accumulation of fluorescence was only observed in the tumor xenograft injected with the fluorescently-labeled miRNA/atelocollagen complex by IVIS.

in the control-miRNA/atelocollagen complex group was $1,938.5 \mathrm{~mm}^{3}$, while that in the miR-375/atelocollagen complex group was $680.6 \mathrm{~mm}^{3}$. The growth of the T.Tn xenografts was therefore reduced by $64.9 \%$ (Fig. $4 \mathrm{~A}-\mathrm{C}$ ). 
A

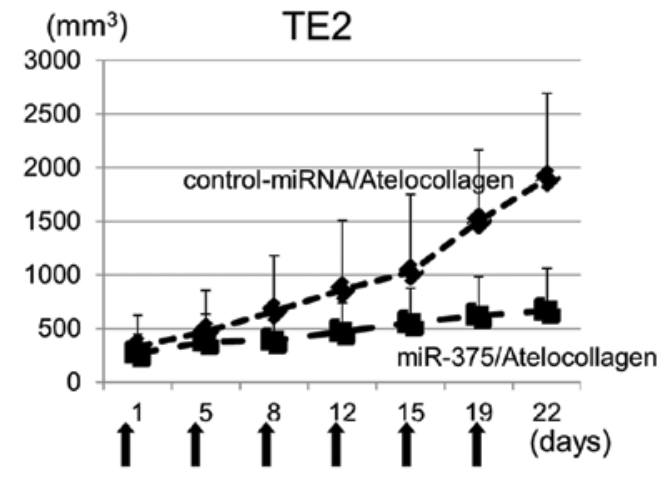

C

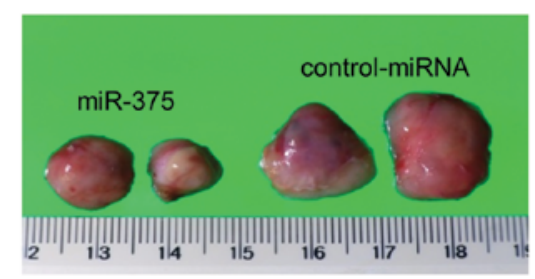

B

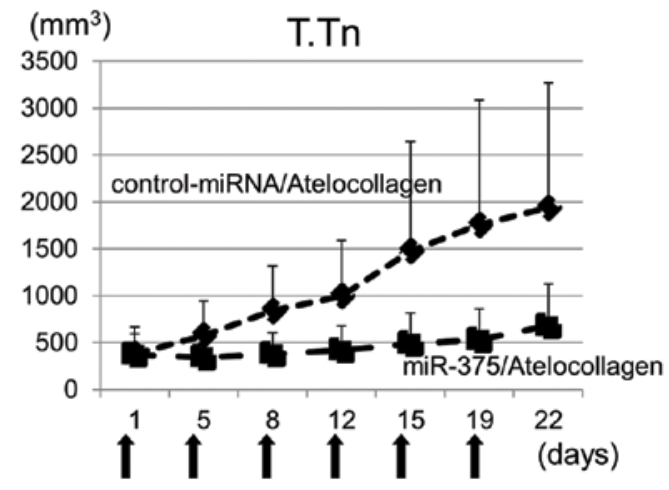

T.Tn

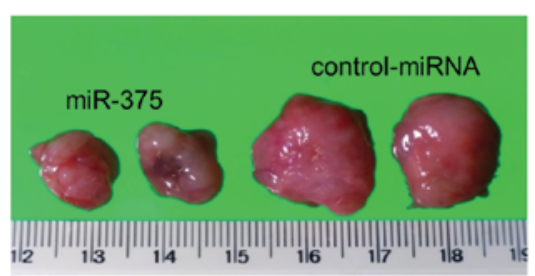

Figure 4. (A) The results of the in vivo assay using the non-viral delivery system to examine the antitumor effect of microRNA-375 (miR-375). The TE2 and T.Tn tumor-bearing mice were injected with $200 \mu \mathrm{l}$ of miR-375/atelocollagen and control-miRNA/atelocollagen complex by subcutaneous (s.c.) injection. The treatment was performed twice a week for a total of six injections. The arrows indicate the days the mice were treated. The average volume of TE2 xenografts in the control-microRNA (miR)/atelocollagen complex group was $1,900.8 \mathrm{~mm}^{3}$ on day 22 , while that of the miR-375/atelocollagen complex group was $668.0 \mathrm{~mm}^{3}$. The data points indicate the average of tumor sizes. (B) The average volume of T.Tn xenografts in the control-miRNA/atelocollagen complex group was $1,938.5 \mathrm{~mm}^{3}$ on day 22 , while that of the T.Tn xenografts in the miR-375/atelocollagen complex group was $680.6 \mathrm{~mm}^{3}$. (C) The TE2 and T.Tn xenograft tumors removed on day 22 are shown. From the upper left panels, the xenografts were TE2 treated with: miR-375/atelocollagen, miR-375/atelocollagen, control-miRNA/atelocollagen and control-miRNA/atelocollagen. From the lower left panels, the xenografts were T.Tn treated with: miR-375/atelocollagen, miR-375/atelocollagen, control-miRNA/atelocollagen and control-miRNA/atelocollagen.

The MRNA expression levels of $L D H B$ and $A E G-1 / M T D H$ were downregulated in xenografts treated with miR-375. The $L D H B$ mRNA expression of the TE2 xenografts treated with miR-375 was significantly downregulated $(\mathrm{P}=0.0067)$. The level of the T.Tn xenografts treated with miR-375 group was not significantly suppressed. There were no significant differences in the AEG-1/MTDH mRNA expression levels between the miR-375 and control groups. However, there was a tendency for the $L D H B$ expression of T.Tn xenografts and the $A E G-1 / M T D H$ expression of TE2 and T.Tn xenografts to be downregulated compared with the control groups $(\mathrm{P}=0.4240, \mathrm{P}=0.1977, \mathrm{P}=0.2549)(\mathrm{Fig} .5)$.

\section{Discussion}

Previously we reported that there was HDACI-induced miR-375 overexpression in ESCC cell lines (18). In the present study, we found that the miR-375 expression in ESCC was lower than that in the normal epithelium. miR-375 has a tumor-suppressive function in ESCC cells, and miR-375 downregulated $L D H B$ and $M T D H$ in ESCC cell lines. Kong et al previously revealed that the downregulation of miR-375 was frequently detected in primary ESCC, which was significantly correlated with advanced stage disease, distant metastasis, a poor overall survival and a shorter disease-free survival (19). In addition, a recent study estimated the expression of miR-375 in ESCC cell lines and tissues using a tissue microarray (TMA) that included 300 cases and confirmed the findings by
miRNA in situ hybridization (MISH) (20). The MISH results also showed that miR-375 was significantly associated with an advanced clinical stage, tumor metastasis and a poor outcome of ESCC $(19,20)$.

In this study, only lymphatic vessel invasion was found to significantly correlate with the high expression of miR-375. However, we found that a low expression of miR-375 was significantly correlated with a poor prognosis in our 85 patients. It might therefore be possible to use the level of miR-375 expression as a prognostic index for ESCC patients. Of interest, miR-375 might be regulated by epigenetic events, including histone acetylation. Supporting this possibility, in our previous study, miR-375 expression was restored by a HDACI in ESCC cells.

$L D H B$ and $A E G-1 / M T D H$ were both identified as miR-375-targeted genes in our previous study. AEG-1/MTDH has been indicated to play a key role in the progression, invasion, metastasis and the resistance to chemotherapies of various types of tumors (21). In addition, the overexpression of $A E G-1 / M T D H$ is considered to be a valuable marker of ESCC progression (22).

In contrast to $A E G-1 / M T D H$, there have been only a few reports on whether $L D H B$ expression is related to the progression of cancers $(23,24)$. Our previous report showed that ESCC clinical specimens exhibited a higher level of LDHB expression at both the mRNA and protein levels compared with the normal esophageal epithelium. Kaplan-Meier curves 
TE2
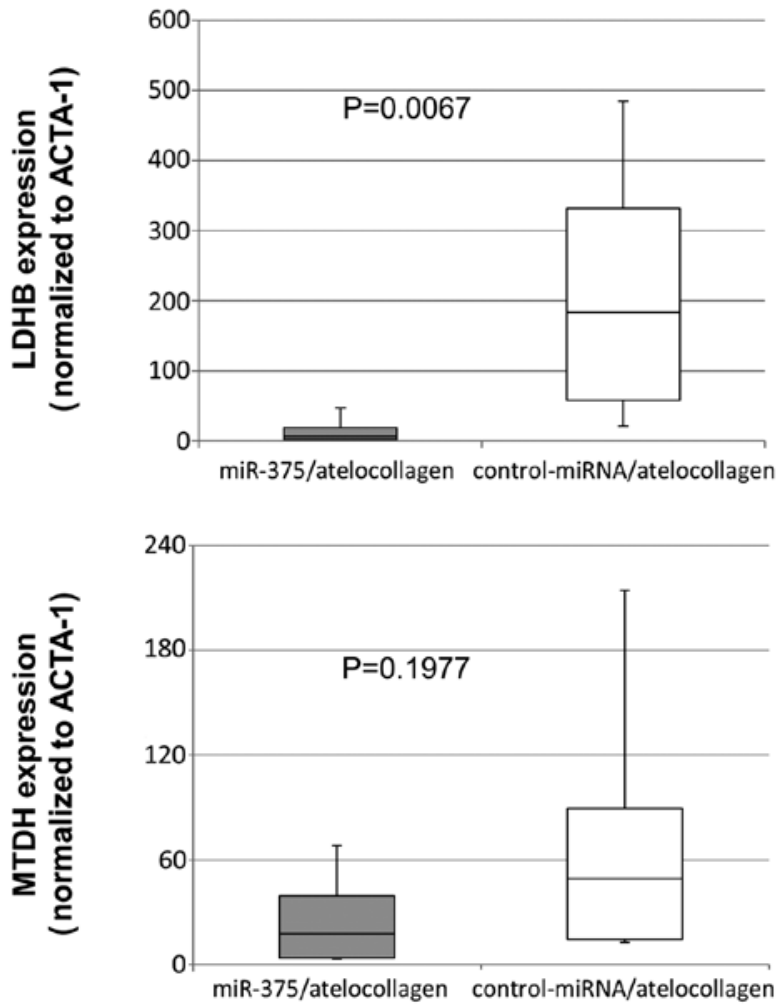

T.Tn
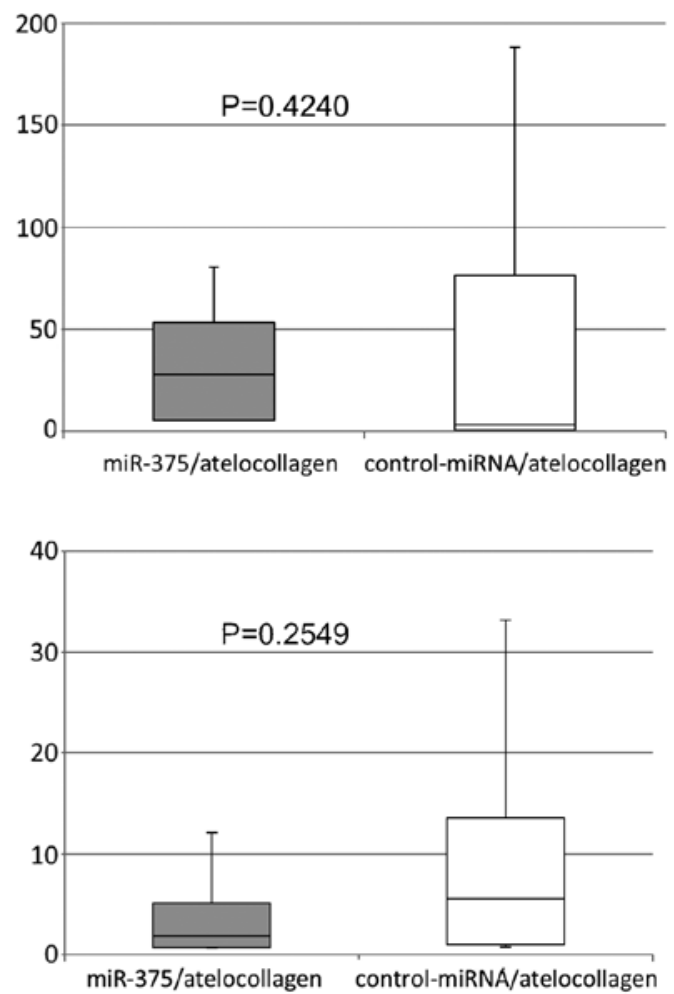

Figure 5. The LDHB mRNA expression of TE2 xenografts in the microRNA-375 (miR-375) group was significantly downregulated compared with the control-miRNA group $(\mathrm{P}=0.0067)$. The expression in the T.Tn xenografts in the miR-375 group was not significantly suppressed $(\mathrm{P}=0.4240)$. As shown in the lower diagrams, there were no significant differences between the AEG-1/MTDH mRNA expression in the miR-375 and control groups $(\mathrm{P}=0.1977$, $\mathrm{P}=0.2549$ ). However, there was a tendency for the LDHB expression of T.Tn xenograft and the AEG-1/MTDH expression of the TE2 and T.Tn xenografts to be downregulated compared with the control groups.

and log-rank tests revealed that positive immunoreactivity for the LDHB protein had a tendency to indicate a poor prognosis. Although it was verified that $L D H B$ and $A E G-1 / M T D H$ were targeted by miR-375, and that these genes might act as oncogenes, the correlation between the miR-375 expression and $L D H B$ and $A E G-1 / M T D H$ expression levels in ESCC clinical specimens was unclear. Therefore, in the present study, we evaluated the correlation between the miR-375 expression and either the $L D H B$ or $A E G-1 / M T D H$ mRNA expression in ESCC specimens. We found that there was a significant inverse correlation between the expression of miR-375 and $L D H B$. Regarding $A E G-1 / M T D H$ mRNA expression, there was a tendency for an inverse correlation with the miR-375 expression. These results confirmed that miR-375 regulates $L D H B$ and $A E G-1 / M T D H$ in clinical specimens and showed there is a possibility that $L D H B$ and $A E G-1 / M T D H$ play a role as oncogenes in ESCC.

Although the use of miR-based therapy appears to be an effective strategy, there are unresolved issues, including the lack of tissue specificity, absence of an optimal delivery system, poor cellular uptake, and risk of systemic toxicity (3). Regarding miR-375, several studies have indicated that this miRNA has anticancer effects against various cancers. However, only one previous report exists so far on evaluation of the antitumor effect of miR-375 in vivo (14). It was revealed that therapeutic administration of cholesterol-conjugated 2'-O-methyl-modified miR-375 mimics (Chol-miR-375) could significantly suppress the growth of hepatoma xenografts in nude mice (14). Since no previous reports had examined the tumor-suppressive effect of miR-375 in vivo for ESCC xenografts, we determined whether miR-375 was effective for ESCC in vivo using an atelocollagen complex to deliver the miR-375.

Atelocollagen, which is prepared from the bovine dermis, increases the cellular uptake, nuclease resistance and the prolonged release of nucleic acids in various disease models in vivo (25-27). Previous studies have already shown the clear therapeutic efficacy of atelocollagen-mediated in vivo delivery of nucleic acids (25-27). In this study, we validated that the miR-375/atelocollagen complex could significantly suppress the growth of ESCC xenografts.

Although major barriers to the clinical application of miR-based therapeutics still exist, the administration of tumor-suppressive miRNA using a non-viral delivery system might provide a powerful new strategy for cancer therapy (3).

It was also found that the low expression of miR-375 was significantly correlated with a poor prognosis in ESCC patients. A significant inverse correlation between the expression of miR-375 and $L D H B$ was observed, suggesting that $L D H B$ may play a role as an oncogene in ESCC. Moreover, we validated that the miR-375/atelocollagen complex significantly suppressed the growth of ESCC xenografts. The administration of a tumor-suppressive miRNA using a non-viral delivery system might be a powerful treatment for cancer. 


\section{Acknowledgements}

We would like to thank the members of the Pathology Laboratory of the Department of Frontier Surgery of Chiba University for critical reading of the manuscript.

\section{References}

1. Ruol A, Castoro C, Portale G, et al: Trends in management and prognosis for esophageal cancer surgery: twenty-five years of experience at a single institution. Arch Surg 144: 247-254, 2009.

2. Morita M, Yoshida R, Ikeda K, et al: Advances in esophageal cancer surgery in Japan: an analysis of 1000 consecutive patients treated at a single institute. Surgery 143: 499-508, 2008.

3. Hoshino I and Matsubara H: MicroRNAs in cancer diagnosis and therapy: from bench to bedside. Surg Today 43: 467-478, 2013.

4. Hoshino I, Matsubara H, Akutsu Y, et al: Gene expression profiling induced by histone deacetylase inhibitor, FK 228 , in human esophageal squamous cancer cells. Oncol Rep 18 : 585-592, 2007.

5. Hoshino I, Matsubara H, Hanari N, et al: Histone deacetylase inhibitor FK228 activates tumor suppressor Prdx1 with apoptosis induction in esophageal cancer cells. Clin Cancer Res 11 7945-7952, 2005.

6. Hoshino I and Matsubara $\mathrm{H}$ : Recent advances in histone deacetylase targeted cancer therapy. Surg Today 40: 809-815, 2010.

7. Bartel DP: MicroRNAs: genomics, biogenesis, mechanism, and function. Cell 116: 281-297, 2004.

8. Hua Z, Lv Q, Ye W, et al: MiRNA-directed regulation of VEGF and other angiogenic factors under hypoxia. PLoS One 1: e116, 2006.

9. Nissan T and Parker R: Computational analysis of miRNAmediated repression of translation: implications for models of translation initiation inhibition. RNA 14: 1480-1491, 2008.

10. Eulalio A, Huntzinger E, Nishihara T, Rehwinkel J, Fauser M and Izaurralde E: Deadenylation is a widespread effect of miRNA regulation. RNA 15: 21-32, 2009.

11. Xu X, Chen Z, Zhao X, et al: MicroRNA-25 promotes cell migration and invasion in esophageal squamous cell carcinoma. Biochem Biophys Res Commun 421: 640-645, 2012.

12. Kinoshita $\mathrm{T}$, Nohata $\mathrm{N}$, Yoshino $\mathrm{H}$, et al: Tumor suppressive microRNA-375 regulates lactate dehydrogenase B in maxillary sinus squamous cell carcinoma. Int J Oncol 40: 185-193, 2012.

13. Ward A, Balwierz A, Zhang JD, et al: Re-expression of microRNA-375 reverses both tamoxifen resistance and accompanying EMT-like properties in breast cancer. Oncogene 32: $1173-1182,2013$
14. He XX, Chang Y, Meng FY, et al: MicroRNA-375 targets AEG-1 in hepatocellular carcinoma and suppresses liver cancer cell growth in vitro and in vivo. Oncogene 31: 3357-3369, 2012.

15. Lee EJ, Gusev Y, Jiang J, et al: Expression profiling identifies microRNA signature in pancreatic cancer. Int J Cancer 120 1046-1054, 2007.

16. Dettmer M, Perren A, Moch H, Komminoth P, Nikiforov YE and Nikiforova MN: Comprehensive MicroRNA expression profiling identifies novel markers in follicular variant of papillary thyroid carcinoma. Thyroid 23: 1383-1389, 2013.

17. Nguyen HC, Xie W, Yang M, et al: Expression differences of circulating microRNAs in metastatic castration resistant prostate cancer and low-risk, localized prostate cancer. Prostate 73: 346-354, 2013

18. Isozaki Y, Hoshino I, Nohata N, et al: Identification of novel molecular targets regulated by tumor suppressive miR-375 induced by histone acetylation in esophageal squamous cell carcinoma. Int J Oncol 41: 985-994, 2012.

19. Kong KL, Kwong DL, Chan TH, et al: MicroRNA-375 inhibits tumour growth and metastasis in oesophageal squamous cell carcinoma through repressing insulin-like growth factor 1 receptor. Gut 61: 33-42, 2012.

20. Li J, Li X, Li Y, et al: Cell-specific detection of miR-375 downregulation for predicting the prognosis of esophageal squamous cell carcinoma by miRNA in situ hybridization. PLoS One 8: e53582, 2013.

21. Hu G, Wei Y and Kang Y: The multifaceted role of MTDH/AEG-1 in cancer progression. Clin Cancer Res 15: 5615-5620, 2009.

22. Yu C, Chen K, Zheng H, et al: Overexpression of astrocyte elevated gene-1 (AEG-1) is associated with esophageal squamous cell carcinoma (ESCC) progression and pathogenesis. Carcinogenesis 30: 894-901, 2009.

23. Kinoshita T, Hanazawa T, Nohata N, Okamoto Y and Seki N: The functional significance of microRNA-375 in human squamous cell carcinoma: aberrant expression and effects on cancer pathways. J Hum Genet 57: 556-563, 2012.

24. Chen Y, Zhang H, Xu A, et al: Elevation of serum l-lactate dehydrogenase B correlated with the clinical stage of lung cancer. Lung Cancer 54: 95-102, 2006

25. Inaba S, Nagahara S, Makita N, et al: Atelocollagen-mediated systemic delivery prevents immunostimulatory adverse effects of siRNA in mammals. Mol Ther 20: 356-366, 2012.

26. Banno H, Takei Y, Muramatsu T, Komori K and Kadomatsu K: Controlled release of small interfering RNA targeting midkine attenuates intimal hyperplasia in vein grafts. J Vasc Surg 44: 633-641, 2006.

27. Takei Y,Kadomatsu K, Goto T and Muramatsu T: Combinational antitumor effect of siRNA against midkine and paclitaxel on growth of human prostate cancer xenografts. Cancer 107: 864-873, 2006 